\title{
Terrorism and maritime shipment of nuclear material
}

\author{
R. C. Smith*
}

\begin{abstract}
Opponents of the nuclear industry often claim that material in transit is vulnerable to attack by terrorist groups who might seek to take the cargo and make a bomb, or otherwise cause a radiological incident. This paper lays out a range of conceivable objectives or attack scenarios in the context of maritime transportation and examines these in the light of what is known of the relevant security arrangements. It concludes that these arrangements provide a very substantial deterrent to any attempt at diversion or sabotage and that any such attempt would have little prospect of success, beyond the immediate media impact of whatever might have occurred.
\end{abstract}

Keywords: Terrorism, Maritime, Sea, Nuclear, Security

\section{Introduction}

It seems that almost every maritime shipment of nuclear materials is accompanied by dramatic claims that the cargo (or ship) is vulnerable to sabotage or diversion by terrorists (with disastrous consequences), although what these terrorists might do, or attempt to do, is seldom made clear. As a consequence, the public is left with vague and ill defined fears and little understanding of what the real risk might be. The present article aims to review the whole range of possibilities: different materials and different quantities; and, particularly, the specific details of the transport arrangements, with a view to identifying what might be attempted, in what circumstances, and with what prospects of success. Critics also often include concerns about the possibility of a purely accidental release of nuclear material. This was the subject of an earlier paper by this author. ${ }^{1}$ It has also been the subject of a number of extensive expert reports. It will not be pursued further here.

Possible targets for terrorism range from relatively small consignments of radioactive materials (such as radioactive sources), which are dispatched with other materials on a journey which includes a maritime component, to nuclear consignments in shipping containers, which are transported along with other containers (cargoes such as yellow cake, or uranium hexafluoride, or spent fuel from a research reactor), to substantial quantities of nuclear material carried on dedicated ships. The dominant company here is Pacific Nuclear Transport Ltd (PNTL), which operates a fleet of ocean going nuclear carriers that have been used mainly to take material between Europe and Japan. PNTL ships were also used in the 2004/2005 transfer of plutonium from the United States to France and Mixed Oxide fuel (MOX) back from France to the United States. This

Department of Political Science and Public Policy, University of Waikato, Private Bag 3105, Hamilton 3240, New Zealand

*Corresponding author, email rjsmit@waikato.ac.nz latter category (large quantities of nuclear material carried on ships specially designed for the purpose) has been the most productive of public concern (however ill founded) and this will be the main focus of the discussion to come.

Even here, though, the range of possibilities is wide and the nature of the supposed danger is different in different cases. Cargoes in this case may be separated military plutonium (the raw material for weapon pits, or material from dismantled weapons); separated civilian plutonium (from civilian reprocessing activities); spent fuel (containing civilian plutonium); MOX fuel (containing civilian or military plutonium, diluted with depleted uranium and made up into MOX fuel rods); or fission products held in solid suspension. In the case of substantial long distance cargoes of plutonium containing material (other than spent fuel) the relevant regulatory requirements that are applicable to a state that is signatory to The Convention on the Physical Protection of Nuclear Material include the provision of an escort vessel. ${ }^{2}$ For PNTL, this requirement is met by the utilisation of a second, identical, cargo vessel. Consignments of highly enriched uranium (HEU) are also of interest in view of their greater potential suitability (compared to plutonium) for the production of an improvised nuclear device (IND). It is assumed that this highly enriched uranium is most likely to be contained in made-up fuel rods for research reactors (rather than dispatched as the pure oxide, or even the metal) and carried in shipping containers on commercial vessels, or, perhaps, consigned by air.

The range of theoretical possibilities for what terrorists might aim to do is equally wide. Most obviously, they might attempt to seize a cargo of weapons grade plutonium, or uranium, and make a nuclear weapon, or weapons. The extent to which civilian ('reactor grade') plutonium is suitable for weapon fabrication is a matter for debate but insofar as it is possible to create some sort of nuclear explosive device from this material (with whatever limitations) this is also a risk. As noted above, civilian spent fuel rods 
and fresh MOX rods also contain plutonium of one kind or another. They could thus be a starting point for weapon fabrication. However, they would require a significant amount of processing to separate the small percentage of plutonium (assuming appropriate technology to be available), and, even then, in the case of civilian sourced plutonium the terrorists might have a material of dubious value to them. The mixture of fission products contained in shipments of separated high level waste is of no use for the production of nuclear explosive devices, though it could be used for the assembly of radiological weapons (as could any radioactive source, including the plutonium sources mentioned above). Spent fuel also contains plutonium but in this case it is mixed (amongst other things) with the very radioactive products of uranium fission. This is a very substantial barrier to diversion of nuclear weapons purposes.

There is another range of theoretical possibilities for terrorist action in regard to maritime shipments of radioactive material, which do not entail actual removal of the material from the ship. These are important since the conditions of transport (especially in the case of dedicated ships) would make the latter operation extremely difficult. Given that the cargo remains on the ship, terrorists might attempt to take the ship to some location (or take the ship over in that location) and then sink it, or detonate a conventional explosive in it, or start a fire, or threaten to do any of these things unless demands are met. Of course, none of these activities would result in a nuclear explosion but they might result in the release of nuclear material into the environment. The final scenario set that is considered is the possibility of a suicide assault on the nuclear-cargo carrying ship itself, in the manner of the attack on the American destroyer, Cole (2000), and the later, similar attack on a French oil tanker (Limburg), or something similar, by aerial or subsurface means. Again, the possible consequences, in terms of the release of nuclear material, are evaluated. It needs to be noted that insofar as they concern shipment on dedicated ships, none of the possibilities outlined in the summaries above has ever been exemplified in some 50 years experience of nuclear transport by sea. This tells us something in general about the level of risk (although it must also be recognised that the aspirations and capabilities of terrorist groups do evolve). To go beyond this we need to look at the main possibilities in a detailed way.

\section{Seizing nuclear cargoes from dedicated ships (or seizing ships, themselves)}

The scenarios that have most exercised the minds of commentators and protesters are those in which dedicated nuclear cargo ships are assaulted with a view to seizing the ship, or its cargo. This came particularly to the fore, in the case of the late 2004 shipment of weapons grade plutonium from the US port of Charleston to the French port of Cherbourg on the PNTL ships Pacific Pintail and Pacific Teal ${ }^{3}$ (in an operation called colloquially, 'Eurofab'). Of this Greenpeace said, that it was 'an invitation to catastrophe: either a radioactive leak or an attempt by a terrorist group to seize the shipment and make a nuclear bomb of its own'. This latter scenario, in which the envisaged perpetrators board the ship and take control of it, is the one that we are immediately concerned with here. The possibility that they might, then, proceed to make a nuclear weapon, or weapons, (or make any other use of their position in control of the ship) is considered later.

The envisaged operation can be broken down into a series of stages. In the first place, the terrorists would need to locate and approach the ships. They would then need to board them and overpower the crew. Therefore, how easy would this be? To begin with, it needs to be noted that in the specific case of the September 2004 shipment (Charleston, South Carolina to Cherbourg, France) there was no stopping at intermediate ports and no passing through narrow straits, which might have provided an easier opportunity for interception. This is also true of MOX shipments from Europe to Japan, following reprocessing of Japanese spent fuel in Britain or France. Therefore, in all such cases, the attack must take place at either end of the voyage (where extra security is available from shore based or coastal assets, as it was, for example, when the ships left Charleston), or in mid ocean. Details of this were provided in a letter from the US Department of Homeland Security to Congressman Edward Markey on 8 September $2004 .^{4}$ The letter refers to Coast Guard cutters, aircraft and 'other law enforcement and Navy assets'. These security arrangements, together with those for the overland shipment of the material in the United States, are described in a report prepared for Greenpeace International and accepted as more than the minimum required by IAEA regulations (and, as such, satisfactory). ${ }^{5}$ The corresponding arrangements at the French end were equally stringent, with French special forces on board the ships from the 20 mile limit and extensive back-up arrangements for the land component. In a midocean situation, the logistical burden on the terrorists is much greater (they need a larger vessel and, presumably, lighter attack craft, as well) and, of course, they need to find their quarry. Reports of attempted interceptions by protest ships of other shipments on the high seas suggest that this may not be easy. Of course, as far as is known, there have been no terrorist attempts to intercept nuclear ships and it is notable that the two suicide attacks on other ships (the Cole and the Limburg) took place in harbour or close to shore. Distance from land (and speed) is ultimately the best guarantee of security. Would-be attackers need to be able to place themselves ahead of their quarry, and they really only get one shot at interception. On the other hand, their quarry has (in mid ocean) a wide range of possible tracks and it can be presumed that PNTL ships would be taking full advantage of that. The time taken for the outward voyage from Charleston suggests that the ships did not take the shortest possible route.

Notwithstanding the major difficulty that terrorists might have in locating their quarry, it will now be presumed for the sake of argument that the terrorists have found the ships. They now need to approach without being detected. This is going to be extremely difficult. The PNTL ships are equipped with modern radar systems and night vision capability; in the case of plutonium cargoes, there are two ships that will be hard to distinguish at a distance (and only one may have the cargo). In addition, there are redundant systems on each 
of the ships, just in case of equipment failure. The ships also carry extra crew over what might be expected in an ordinary civilian cargo ship and the operators also err on the side of caution in the matter of personal qualifications, so that the possibility that a particular skill is not available (through accident or illness) is reduced to minimal levels. Thus, the chances that the would-be attackers could approach undetected are extremely small. This is important since the PNTL ships are known to be armed with three $30 \mathrm{~mm}$, rapid fire naval guns. These would present a considerable problem to any vessel attempting an unauthorised approach and this may be thought to be a sufficient deterrent to any but the most determined and prepared. The terrorists would need to deploy undetected and in mid ocean, several armoured and well armed attack vessels with a substantial force to man them. It also needs to be noted that the PNTL ships, when carrying plutonium cargoes (including reactor grade material in the form of MOX), carry an additional complement of armed police officers (the Civil Nuclear Constabulary, CNC), who have access to a variety of weapons, including rifles, shotguns and handguns, etc., as well as protective equipment such as body armour and gas masks. They also have available 'non-lethal response' methods, which include high pressure water cannon. All this surveillance and defensive capability is coordinated through a Vessel Alarm Station. It is from here that operations would be controlled in the event of a security threat of the kind being envisaged.

This suggests that the terrorist boarding party might have some difficulty even after it had got to its quarry. They now need to get aboard a moving vessel, with nobody likely to be throwing down a ladder. In fact, the attackers are going to need some sort of extendable pole ladder at this point. Operating this in the open ocean while travelling at around 14 knots and with the possibility of being fired upon from above would seem to present an insuperable challenge. There would be only one way around this and that would be to use helicopters for the assault. These would need to be large, in order to carry an attacking force of such a size that it would not be immediately overwhelmed by the defenders. This, in turn, would require a substantial platform from which to fly the helicopters and would raise the level of sophistication required for the operation yet another notch (although the possibility of deploying helicopters would vastly improve the search capability of the assault force). There is also the difficulty that the PNTL ships have defensive systems that would constitute a substantial deterrent to a helicopter landing, which means that an airborne assault force would need to rappel down to reach the ships. Of course, the operations envisaged here are within the capability of the Special Forces of major states and thus may be said to be theoretically possible for other parties. On the other hand, there are no precedents for this kind of operation by non-state parties and it is scarcely credible that a terrorist organisation (however, well funded) could mount such an extensive and technically sophisticated operation far from shore and without being detected by the relevant security services.

\section{Threat assessments}

Much of the above account of the protective measures available in the sort of case under review is taken entirely from open sources. From briefings given to this author by persons in, or close to, the security agencies in the various countries concerned, it is clear that there are many other security provisions that are not in the public domain, and the total effect of these is to add greatly to the difficulties enumerated above, especially in the most sensitive cases. Collectively, these would seem to present such a challenge to would-be attackers as to make an attack of the kind envisaged extremely unlikely to succeed (or even to be attempted). It also seems clear that the assault ship(s) in this sort of case would be very vulnerable to detection by satellite surveillance systems, or by ships or aeroplanes, depending on circumstances. In the special case of the weapons grade plutonium shipment ('Eurofab'), it seems clear that the track of the PNTL ships was followed very closely so as to monitor the possibility that other unidentified ships were approaching. It is also clear that in this case the PNTL ships were watched over in other ways. Consultations with officials in Washington seemed to confirm that some kind of continuous monitoring of the ships was in place. At one point the somewhat enigmatic observation was made that 'they (the ships) were never alone'. This is the sort of matter that would be included in the official threat assessments that are required for shipments of this kind. These are routinely made by persons in a variety of agencies in the countries, including departments of transport, energy and foreign affairs, as well as the various national intelligence and security bureaux, and, of course, persons from the companies concerned. These consultations and deliberations give rise to comprehensive evaluations of potential threats to the ships or the cargoes, which are called design basis threat assessments (DBTs). These are not public documents, and, in the nature of things, they could not be so. To publish what had been anticipated (and prepared for) would merely be an invitation to potential malefactors to devise something that had not. On the other hand, not publishing DBTs means that the concerned citizen cannot assure himself that every possibility has been thought of. In the opinion of the author, the first principle is the most important among the two. This is particularly so since the second requirement (that everything has been thought of) may be logically impossible to show. How could you know that there was still not something you had not thought about? However, one might be satisfied that the amount of work that had been conducted was such as to reduce the chance of successful terrorist assault to negligible levels.

In the case of less security sensitive cargoes (spent fuel, or separated fission products), there will generally be only one ship (i.e. no escort) and less need for dedicated security personnel to be carried, unless there are intelligence indications to the contrary. In the case of the separated fission products (usually transported in the form of a solid ceramic material in a steel vessel, which is itself contained within a very substantial transport flask), the lower security assessment is based on the fact that the most that this material could be used for is for some sort of radiation dispersal operation, and even then it is in a most unpromising form (from the terrorists' point of view). It could not be the basis of even the most rudimentary nuclear explosive device. Spent fuel certainly contains small amounts of plutonium (in a mixture of isotopes) and even smaller 
amounts of unused uranium 235, from which (in principle) a nuclear explosive could be fabricated, but these are, equally, in a most unpromising form. Not only are they mixed with the extremely radioactive products of fission and a large amount of uranium 238 (from which they would need to be separated), they are also contained within fuel rods from which they are not easy to extract. Apart from the radiation danger, there are also physical factors here. Some spent fuel rods may have been deformed by long exposure to high temperatures in the reactor core. Insofar as this is the case, their contents are not accessible in the way that the fuel pellets in fresh fuel rods would be. In practical terms, the most spent fuel could be used for would be radiological contamination. Whatever else may be said, this is a significantly lesser danger, and thus, it is appropriate to treat such cargoes as less security sensitive.

\section{Greenpeace responses}

It is noteworthy that these security provisions (including the most stringent, as in the weapons grade plutonium case) inevitably fail to satisfy greenpeace and other opponents of the trade. The grounds of this dissatisfaction are made clear in a report commissioned by Greenpeace International and conducted by their French and British consultants (WISE-Paris and Large and Associates). In the view of these consultants, the security arrangements did not go far enough, given the heightened risk of terrorism since September 2001. It was said that the United Kingdom authorities, who were responsible for the maritime component of the 2004/ 2005 plutonium transfer, did not have a 'definitive list of DBTs' (although how they might have known this is not at all clear) and appeared to be resistant to planning for possible terrorist actions'. Specifically, they noted that the regulatory requirements for this kind of shipment ${ }^{6}$ specify that 'one or more escorts' must be provided and that, even in this most sensitive case, that was all that was provided. In the view of the author, the latter criticism was very wide of the mark. It was simply that the full security plan was not (for obvious reasons) made public. The 'Eurofab' shipment was a special case and there were significant additional security provisions in place. Apart from anything else, it would have been undesirable to publicly establish new norms which might then be expected in the case of less sensitive shipments, such as those containing commercial plutonium or MOX fuel.

In the general case, and from a strictly logical point of view, it is undeniable that there would be more security if there was additional security support but, equally, it may be doubted whether the expense of such additional steps would be justified by the quotient of additional security that they would buy. Particularly, this would seem to be the situation, having regard to the challenges that already confront the would-be terrorist, on the basis of the known security arrangements, and in the absence of specific evidence of the possession by terrorist groups of the sort of capability that could overcome them. Also, it may be doubted whether Greenpeace criticisms of the specifics of the security arrangements are entirely sincere. They want to prevent the activity (shipments of nuclear material, and, more generally, nuclear operations of all kinds) and one may conclude that no amount of additional provisions would really satisfy them.

\section{Using cargo}

Notwithstanding the above arguments, which tend to suggest that seizure of a dedicated ship with its nuclear cargo is very unlikely to succeed, the discussion will now continue on the basis of exactly that assumption, i.e. that the transport vessel has been seized. At this point the scenarios diverge into those that entail separation of the cargo from the ship and those that do not. As far as the former is concerned, it should be noted that commercial cargoes of spent fuel, MOX, or high level waste (HLW), on the Japanese run, are generally contained within very substantial transport flasks, which weigh over 100 tons. The immediate issue is whether the contents can be removed without moving the transport flask. If they cannot, then the flask itself must be taken. As far as the opening flasks is concerned, there are two problems. The first is that there is generally insufficient space in the hold of the ship to remove the very substantial safety protection on either end of the cask and that specialist equipment is necessary to remove flask lids. The thick walls of the flask would also make cutting into it an extremely protracted exercise and, even then, the size of the internal packaging is going to make removal of the contents very difficult. This is very significant, since 'delay' is a central element in the overall security strategy. That the ship has been taken will be known from a very early stage and there are arrangements in place to alert operators to any false messages of reassurance. From the point when the first alarm report is received (or if the communications systems fail to operate as intended), serious forces are likely to be converging on the scene (depending on the circumstances and the location).

There is another factor here. If the cargo is spent fuel or separated fission products (high level waste), opening the package is likely to expose the attackers to huge doses of gamma radiation and the possibility of instant death for those involved. These sorts of materials can only be dealt with in remote handling facilities.

As far as removing the unopened flasks is concerned, it should be noted that, although the ships are fitted with a substantial hoist system that is capable of lifting the hold covers, it is not capable of lifting the flasks themselves. In the case of plutonium or MOX shipments, even these hoists are removed, so that opening the hatches in mid ocean would require the attackers to have brought their own heavy lifting equipment and this would be very substantial if it were to be also capable of swinging a 100 ton flask out over the side. This adds another monumental logistical problem if the cargo is to be removed in mid ocean. The crane is going to be a large and towering object, difficult to get hold of and difficult to move without being noticed. Even so, it would be a fraught operation, assuming that it is being conducted in mid ocean (the author has some long past but still vivid experience of unloading equipment of this sort of weight over the side of a tank landing ship and into smaller landing craft). Of course, the alternative is to take the ship and its cargo to a suitable port with appropriate lifting equipment. This course of action has its own obvious problems. It would clearly take a number of days to get to such a suitable port (still presuming that the interception has taken place on the high seas) and, all the while, the location of the ship 
would be hard to conceal. As noted above, PNTL vessels have a strict reporting system when engaged in these kinds of voyage, so that the fact that there was a serious problem would be known to the $24 \mathrm{hr}$ Communications Centre almost immediately. The risk of interception, before any unloading could take place, would thus be very great.

\section{Terrorist use of ship and cargo}

The starting assumption here is that terrorists have taken control of the ship and its cargo and that, even if the position of the ship continues to be known, counter action is inhibited by a threat, from the terrorists, to take further action against it. The possibilities here are that the ship is scuttled, or set on fire, or that a large explosion is set off on the ship (which may also result in either or both of the former possibilities).

Some scenarios that involve the ship and its cargo at the bottom of the ocean have already been extensively studied in the context of accidental events, such as severe collision or grounding. In the specific case of fresh MOX fuel, the results of a series of technical studies by the Central Research Institute of the Electric Power Industry of Japan (CRIEPI) were reported in $1998 .^{7}$ The studies covered: the performance of the transport cask; the performance of the cladding around the MOX pellets; and, assuming both of these to have failed, on the rate at which nuclides in the package would leach into the surrounding water. The conclusions were unequivocal. The intact transport casks were resistant to water pressure down to $7000 \mathrm{~m}$ and thus the casks were not expected to rupture and expose their contents. Tests on the MOX fuel rods revealed a similar resistance to breach down to the same depth. In the extremely unlikely event that both of these barriers failed, it would be expected that radioactive material would begin to slowly leach into the immediate environment but at a rate that would add only negligibly to the ambient radioactivity. In terms of potential radiation exposure, doses to be expected were fewer than one-millionth of the relevant ICRP dose equivalent limit. Similar studies have been undertaken of the parallel risks from casks containing vitrified fission products (high level waste). ${ }^{8}$ Here again, the robust nature of the transport packaging and the low leach rate from the vitrified material suggested negligible risk. In fact the probability that exposed individuals would receive doses that exceeded recommended limits for members of the public, as a result of collision or accident, was put at $2 \times 10^{-18}$. The authors of the study also noted that salvage possibilities also made it extremely unlikely that there would be any significant public exposure in any event.

The shipment casks used in the case of the US plutonium sent to France in October 2004 and in the returning MOX fuel assemblies in 2005 were significantly less massive than the casks used in other cases ( $1 \frac{1 / 2}{2}$ and 4 tons respectively), so that, all else being equal, they would present less of a problem to move. The casks were nonetheless of very substantial construction, consisting, in the case of the plutonium oxide powder, of a concentric arrangement of 'cans', with a carbon steel outer layer. ${ }^{9}$ They were also in a substantial outer container (like an armoured shipping container) from which they would have had to be removed. Together, these cladding materials and the surrounding packaging would provide a substantial barrier to terrorists' access to the active material, notwithstanding that they are significantly less massive than the casks used on the longer voyages to Japan.

In the case of sabotage (as opposed to accident, and thinking now of the more general case, where the nuclear material is not seen as potentially nuclear weapon material) it can be supposed that the terrorists would wish to affect the sinking in coastal or inland waters but it seems evident from the above data that this would scarcely be worth the effort in terms of its environmental impact. Merely submerging the casks would produce no nuclear contamination and, even a systematic effort to breach the transport containers and expose the contents (itself a formidable undertaking in the confines of the ship), would produce low levels of contamination. Sinking in deep waters would have an even smaller environmental impact, although salvage would be more difficult.

After all, what we are left with is fire and explosion. Assuming the ship to have been taken over, fires could be started in various places, with the normal fire fighting mechanisms disabled. Like the immersion contingencies, this contingency has also been studied in the context of accidental fire ${ }^{10}$ and the results of this study may be applied to the supposed terrorist sabotage case. In general, the sort of package used for the transport of nuclear materials is resistant to all but the hottest and most persistent of fires (which are unlikely to occur accidentally in the hold of the ship). ${ }^{11}$ To achieve any breach of the package seals would require the contrivance of high temperatures for a prolonged period. This, in turn, suggests that there would be a need for additional combustible material, which would have to be procured from somewhere and loaded on to the target ship. This would, in turn, suggest further substantial logistical problems. Even at the end of this effort, the amount of radioactive material released to the environment might be trivially small. Taking control of an oil tanker (or, better still from the terrorist's point of view, an LNG tanker) and setting it on fire would seem to be a far better bet, in terms of public spectacle. This point was dramatically underlined by a speaker in a June 2006 energy conference in Darwin, Australia. Professor Yea Byeon-Deok was quoted as saying that a 100000 ton LNG tanker 'has four times the energy potential of the atomic bomb used to hit Hiroshima'. ${ }^{2}$

There is a final possibility to be considered, and that is that terrorists who have taken over the ship use explosive (and, especially, 'shaped') charges to breach the shipping casks and release some quantity of the nuclear material within. The Greenpeace International consultants discussed this possibility at some length in the context of the French overland component of US plutonium shipments to France. In the course of this discussion, they claimed that tests performed by the French nuclear protection institute (IRSN) show that the FS47 cask (as used in the Eurofab case) is vulnerable to breach by advanced modern shaped charge munitions, and that this could result in the ejection of a significant quantity of the plutonium oxide powder (although IRSN deny this). Given the consultants' further claim that such an outcome could be achieved through the deployment of a rocket propelled grenade, it may be that there is some need for further scientific 
testing. More generally, the experts at IRSN are currently engaged in evaluating a whole range of scenarios involving different shipping containers and differing contents against possible modes of assault. Of course, it would not be in the interests of security to make the results of these tests public and, in any case, this can never be a static situation. As in other contexts, the security authorities need to continue to respond to innovation on the part of potential threat groups. On the other hand, there is no need for them to assist the latter by telling them of the progress they have made.

The applicability of this to the maritime context is limited. Breach of the shipping flask from outside the ship would be impossible (the missile would lose much of its momentum and all of its accuracy passing through the double hull of the ship, even if the terrorists knew precisely where to aim). A missile or shaped charge inside the hold might (if the Greenpeace consultants are right) displace some plutonium powder but the ejecta would be held within the hold itself. The scenario in which activities of this kind (in respect of all or most of the packages) are then followed, in a subsequent stage, by further explosions or fire intended to breach the holds, raises the whole operation to a new level of complexity and uncertainty, especially when taken with the difficulties of taking the ship in the first place. It might also add very greatly to the time that would be required to make these various preparations. It also needs to be noticed that the claimed vulnerability of the 'Eurofab' packages would not apply to the much more massive casks used on the Japan/Europe run.

\section{Terrorist attacks on nuclear cargo ships}

There remains the possibility that a ship carrying a nuclear cargo is attacked by ramming it with a small, fast vessel carrying a substantial explosive charge: a maritime suicide attack. This sort of attack has been exemplified in the case of the assault on the USS Cole in Aden in 2000 (12 October) and in the subsequent attack (in October 2002, off Yemen) on the French oil tanker, MV Limburg. There was also a failed attack of this kind on the USS The Sullivans, off Yemen in January 2000. In this case, a boat full of explosives sank before it could reach the ship. Some commentators predict that this is a mode of attack that will become common in the years ahead, on the grounds that maritime transport is presently more vulnerable than air transport. Indeed, it is claimed that 'al-Qaeda may have developed a terrorist naval force of 15-20 vessels' for just this sort of purpose. Other reports, citing 'US intelligence officials', talk of 'between 12 and 300 ships' having been identified. ${ }^{13}$ Other experts, again, are somewhat cynical about these claims.

The question for this study is what might be the dangers to ships carrying nuclear cargoes from an attack of this kind? As far as shipments on dedicated ships are concerned, the first need is to assess their vulnerability to the sort of attack experienced by the Cole and the Limburg. In both cases, media reports suggest that some 400 to $500 \mathrm{lbs}$ of TNT equivalent explosive, packed in a small fibre glass or inflatable craft, was used to tear a hole, several metres across, in the hull of each ship. The impact of the attack in each case suggests that the explosive might have been in the form of a shaped charge. A contemporary report in the London Times (reporter Ian Brodie) hints that the technical sophistication of the attack suggests professional or 'government' involvement. The Limburg was of a modern, double hull construction, with $20 \mathrm{~mm}$ thick side plate. Despite this, inner compartments were breached and there was a severe fire from leaking oil. By contrast, the hull plate on the Cole was only half the thickness, at $10 \mathrm{~mm}$, and in this case there was limited fire. On the other hand, damage to the Cole may have been more structurally severe. Neither ship sank.

It is reasonable to suppose that a similar attack on a PNTL ship would cause similar damage, although the system of $20 \mathrm{~mm}$ steel horizontal collision reinforcement plates between the inner and outer hulls might be expected to dissipate very considerably the blast effect. With no inflammable cargo, significant fire is unlikely and the double hull construction of PNTL ships suggests that there would be a very low risk of sinking. As noted earlier, the extremely robust construction of the transport casks (forged steel up to $250 \mathrm{~mm}$ thick, in the case of cargoes to and from Japan) suggests that it is extremely unlikely that these would be breached. It is even more unlikely that a large hole and a substantial list might permit a container that had somehow become detached to slip out into the sea; and it is also highly unlikely that a container could become detached, since the containers in these ships are tied to the floor of the hold with large bolts. It also needs to be noted that both the Cole and the Limburg were stationary at the time they were attacked (they were alongside, or moored at a buoy) and that PNTL ships in French harbours are protected by a floating barrier, which is intended to prevent just such an assault. In other cases the mooring is completely enclosed.

There is also the possibility of assault by air, as by a small plane packed with explosives (i.e. an aerial suicide attack). Such a plane would be vulnerable to the naval cannon and small arms carried in the case of sensitive cargoes but these could not guarantee that such an attack would fail. In this case, there could be a significant damage to the ship, although it is very unlikely to cause much (if any) release of radioactive material. Again, the extremely robust character of the transport casks would prevent this. Probably the ship would not sink as a result of such an attack, having regard to its special buoyancy features, but even if this happened, the consequence would merely be that the cargo (still in its flasks) would be on the bottom of the sea. If we are presuming attack by a small plane, we must also presume that the attack has taken place not far from land (bearing in mind the likely range of a small plane with a heavy load of explosives). As noted earlier, this would mean that salvage would be relatively straight forward. We might also note that the further the ship was from land, the greater would be the difficulty (for the attacker) in finding it in the first place. There is also the question of where (in relation to the likely track of the ship) the attack aeroplane is actually flying from. Given that we are talking of a light aircraft, this may need to be nothing more than a grass strip. On the other hand, this would significantly restrict the payload and range. If it were assumed that the attack plane was a large commercial aeroplane, specially hijacked for the purpose (i.e. the $9 / 11$ scenario), the consequences of the impact would be greater, though it would still not 
breach the transport flasks. There would also be greater difficulty in coordinating the attack and finding and hitting the target.

At the other end of the scale, there has been speculation about the possibilities for terrorist attacks using scuba divers. Whatever effect they might have in other circumstances, it seems clear from the considerations brought forward in the above discussion that an attack even by several suicide divers, operating together, could hardly deploy sufficient explosive to significantly damage a PNTL ship. In port, the security authorities are also likely to deploy some kind of underwater deterrent capability, which would make an attack of this kind very difficult if not impossible. Of course, it is accepted that whatever turned out to be the reality in a particular case, any attack on a nuclear cargo vessel would be productive of a great deal of comment and potential public alarm (especially if it occurred close to land).

The case of a maritime terrorist attack on a container ship that has some containing radioactive substances among its containers is different again. If such a ship were set on fire there is clearly a possibility that nuclear matter would find its way into the environment. How big this possibility is, and what the danger would be, would depend on the nature of the cargo and the number of containers that actually contained nuclear material. It also needs to be noted that container ships frequently carry significant quantities of hazardous material that is non-nuclear and that the effect of a terrorist assault of the kind envisaged may be more significant for the chemical toxicity of what is released than it is for any radioactive component. The possibilities for this sort of attack are thoroughly explored in an article by Richardson. ${ }^{14}$ Richardson does not discuss the possibility that the nuclear material comes from cargoes on dedicated ships, or that such a ship is 'commandeered' to be used as a radiological 'weapon'.

\section{Conclusion}

The substantive discussions above have encompassed broadly three possibilities for terrorist action against these ships and their cargoes: terrorists might aim to take the ship and separate its cargo; they might take the ship and create some incident involving the ship and cargo together; or, they might aim to assault the ship from outside by explosive or missile (including a suicide aeroplane attack). In the first case, the terrorists need to find the ship, approach it, and successfully board it and subdue the defenders. After this they need to unload the cargo, either in mid ocean, or by taking the ship to a suitable port without being intercepted. The very formidable problems entailed in each of these stages have been elaborated in some detail. It is hard to resist the conclusion that, taken together, they add up to an operation that has an extremely low probability of success, having regard to the known defensive capabilities of the ships concerned and the capabilities that would be required to overcome them. There are also significant problems in turning the material thus secured into a usable device and, if the device is a radiological one, doubts about whether the actual consequences of its use would be worth all the efforts. Even if the cargo that has been seized is plutonium in the form of MOX fuel, there would be a great deal of technically sophisticated processing required to turn that into bomb material, and further difficulties in assembling and delivering the weapon.

Many of the same considerations apply to the second envisaged scenario. Again, the ship needs to be taken and the defenders subdued but in this case there are crucial difficulties in turning ship and cargo together into a plausible threat. In great part, these concern the nature of the cargo itself and the way it is held. The most likely cargo to which this scenario is applicable is vitrified high level waste. This is very radioactive material but there is considerable doubt that it can be turned easily (or at all) into a form that might constitute an environmental threat in the event that it was somehow dispersed. There would be broadly the same problems in separating MOX fuel from its container and cladding, with the added drawback that it is only feebly radioactive. Spent fuel, on the other hand, is certainly highly radioactive (through the presence of the fission products) but it, too, would be difficult to get at and, like the high level waste, very dangerous in the attempt. Without getting any of these materials out of their containment, it is not at all evident that a terrorist event involving significant contamination of the environment could be contrived.

Scenarios in the third category do not require that the ship (or ships) be taken. In this case, there is merely an assault from the 'outside' by missile, fast attack vessel, aeroplane, or frogman. Considerations of what could actually be achieved by such an operation suggest that the effect of the attack is unlikely to be anything more than superficial damage to the ship (although such an assault could have an impact on the operation of the ship by damaging equipment and/or killing crew). On the other hand, the possibility that a dedicated nuclear cargo vessel could be struck by (say) a missile, cannot be excluded. This would be most likely when the ship was close to shore and, perhaps, when 'protest' activity provided the cover for a firing position. More generally, it is also possible that considerations of restraint and proportion on the part of security personnel could inhibit or condition the response to an apparent assault which threatened only minimal damage. However, it does need to be noted here, how far this hypothetical outcome is from the scare scenarios with which we began.

There is a renewed interest in civilian nuclear power. In the context of a growing anxiety about climate change and increasing uncertainty about oil and gas resources, more countries are acquiring (or intending to acquire) nuclear capacity and countries that have it are planning further developments. These factors, together with a desire to internationalise the more sensitive nuclear technologies, seem likely to bring on more shipments of nuclear material to more destinations. It will be important to make sure that this is performed as safely as it can be, both as regards accidents, and as regards the terrorist threat. Present regulatory standards and practices, especially in regard to dedicated ships, such as those operated by PNTL and the Japanese and Swedish utilities, provide very considerable assurance that this is so. There is very little prospect of an attack of the kind envisaged in the above scenarios having any serious consequences beyond the inevitable media frenzy it would undoubtedly provoke. 


\section{References}

1. R. Smith: Polit. Sci., 2002, 54, (1), 5-19.

2. INFCIRC/274 (http://www.iaea.org/Publications/Documents/ Infcircs/Others/inf274r1.shtml), augmented by INFCIRC/225/ Rev.4 (http://www.iaea.org/Publications/Documents/Infcircs/1999/ infcirc225r4c/rev4_content.html)

3. The cargo of $150 \mathrm{~kg}$ of plutonium dioxide was on one of the ships, with the other acting as escort.

4. http://www.house.gov/markey/Issues/ iss_homeland_resp040908.pdf

5. http://www.wise-paris.org/english/reports/040920JointAssessmentIAEA. pdf

6. IAEA INFCIRC/225 and IAEA INFCIRC/274.

7. CRIEPI, 1-6-1, Otemachi, Chiyoda-ku, Tokyo, Japan.

8. J. Sprung et al.: 'Comments on a paper titled "the sea transport of high-level radioactive wastes: unresolved safety issues", Sandia National Laboratories, SAND97-1130, May 1997.
9. National Nuclear Security Administration (NNSA): 'Fabrication of mixed oxide fuel lead assemblies in Europe', November 2003 (DOE/EIS-0229-SA3)

10. J. Sprung et al. (op cit) and IAEA: 'Comments on MEPC39/ INF.15'

11. IAEA: 'Severity, probability and risk of accidents during maritime transport of radioactive material', Report TECDOC-1231, Vienna, Austria, 2001.

12. M. Richardson: 'Security vital in billion-dollar trade', The New Zealand Herald, 26 June 2006, page A 12.

13. JINSA: 'Hazardous seas: maritime sector vulnerable to devastating terrorist attacks', April 1, 2004, available at: www. jinsa.org/

14. M. Richardson: 'A time bomb for global trade: maritime-related terrorism in an age of weapons of mass destruction', Institute of South East Asian Studies, February 2004, available at: http:// www.iseas.edu.sg 